G.V. Bezprozvannych, A.G. Kyessayev

\title{
RELAXATIONS LOSSES IN POLYETHYLENE INSULATION OF COAXIAL CABLE STRUCTURE DURING AGING IN HIGH HUMIDITY CONDITIONS
}

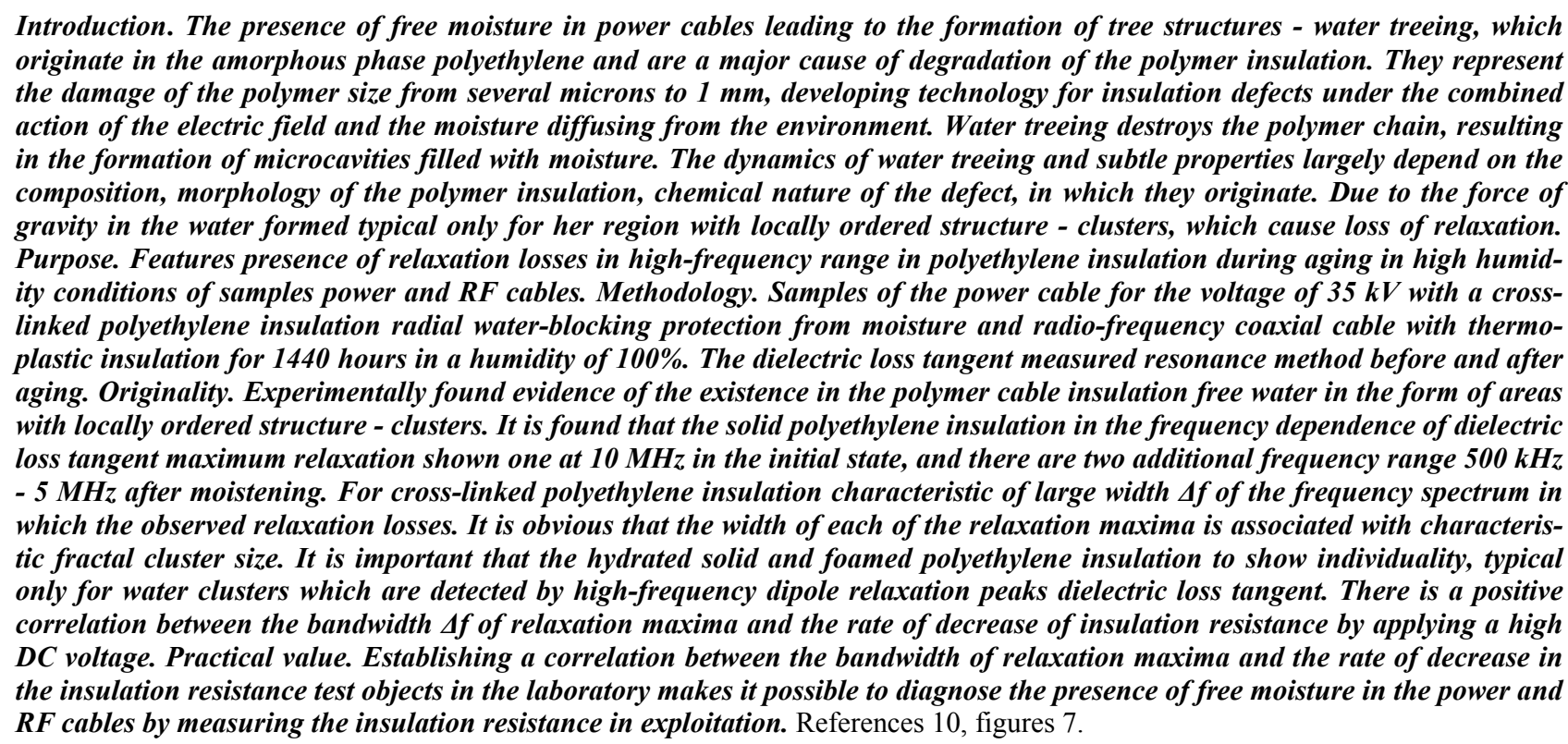

Key words: water treeing, moisturizing cables, solid and foamed polyethylene insulation, dielectric loss tangent, water clusters, relaxation peaks.

Выполнены измерения в диапазоне частот 50 кГц- 20 МГц тангенса угла диэлектрических потерь образцов силового и радиочастотного коаксиального кабелей в исходном состоянии и после увлажнения в условиях $100 \%$ влажности. После старения установлено появление дополнительных релаксационных максимумов для сплошной термореактивной и термопластичной полиэтиленовой изоляции, что обусловлено группированием свободной воды в кластеры соответствующей формы и фрактальной размерности. Для кабелей со вспененной термопластичной полиэтиленовой изоляцией в не состаренном состоянии присуще проявление релаксационных потерь за счет наличия воды в газообразных включениях. Установлена положительная корреляция между шириною полосы релаксационных максимумов и скоростью уменьщения сопротивления изоляции от приложенного высокого постоянного напряжения. Библ. 10 , рис. 7.

Ключевые слова: водные триинги, увлажнение кабелей, сплошная и вспененная полиэтиленовая изоляция, тангенс угла диэлектрических потерь, кластеры воды, релаксационные максимумы.

Introduction. The presence of free moisture in the power cable leading to the formation of tree structures, water treeing (Fig. 1) [1-7], which are generated in the amorphous phase of the polyethylene, i.e. on the boundaries of the grains-crystallites (Fig. 2), and are a major cause of degradation of the polymer insulation. Water treeings are damages of polymer sized from a few microns (Fig. 1, 2) to $1 \mathrm{~mm}$, developing on technological defects of insulation under the combined action of the electric field and the moisture diffusing from environment. Together with moisture aggressive substances penetrate to the insulation. They destroy the polymer chains, resulting in the formation of microcavities filled with moisture.

Dielectric strength in treeing is significantly reduced, which increases the strength on the undamaged part of the insulation and accelerates the process of treeing growth [5]. Aging at the conditions of operation or tests at increased temperature $\left(90{ }^{\circ} \mathrm{C}\right)$ is significantly lower than at lower temperatures $\left(20-40^{\circ} \mathrm{C}\right)$ : water

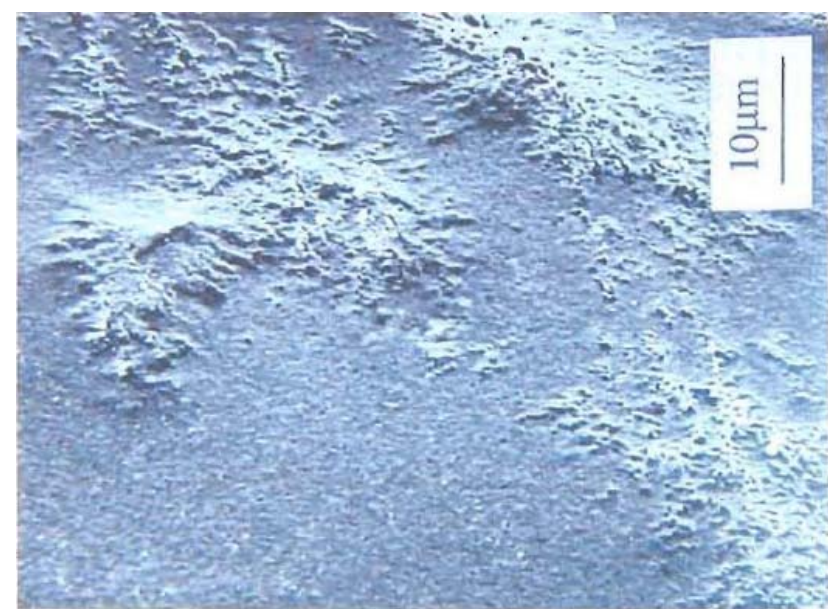

Fig. 1. Photo of emerging water treeing in cross-linked polyethylene insulation of power cable, obtained by power electron microscope [4]

(C) G.V. Bezprozvannych, A.G. Kyessayev 
treeing grows less rapidly. The dynamics of water treeing and their subtle properties largely depend on the composition, morphology of the polymeric insulation, the chemical nature of the defect, on which they originate.
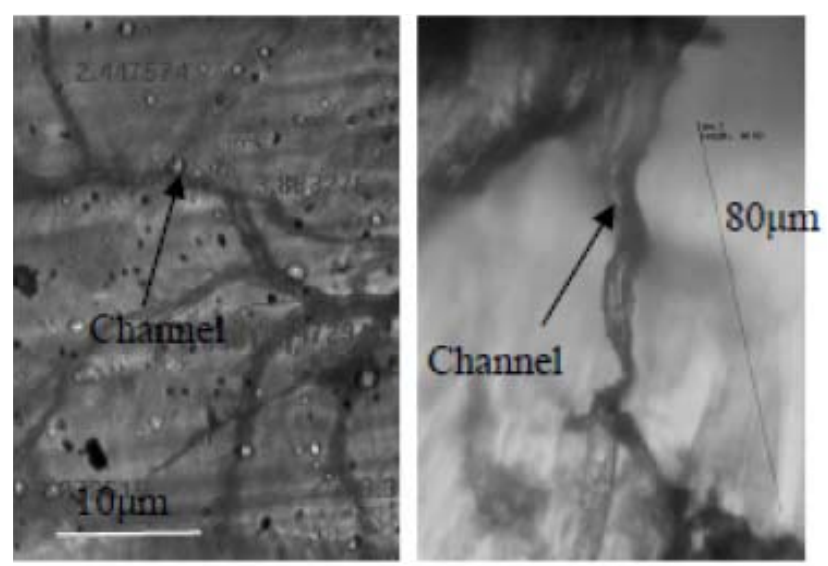

Fig. 2 [6]

Problem definition. Water treeing can be quantitatively described in terms of the fractal dimension, i.e. the concept of the quantity characterizing the geometric structure of stochastic objects [8,9]. Current concepts in this area connected with the fact that most of the natural stochastic structures have so-called scaling symmetry (scale invariance): they are viewed equally at different magnifications (Fig. 3). With the help of the algorithm for constructing the stochastic fractals using iterated function it is possible to model the complex fractal structure of water treeing in polymer cable insulation.

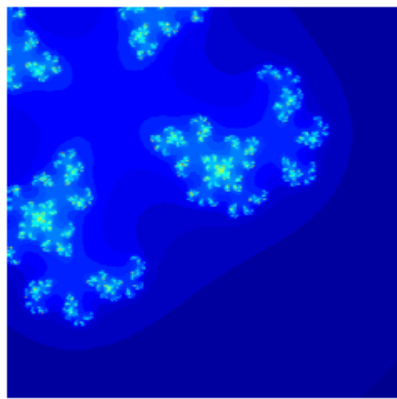

$a$

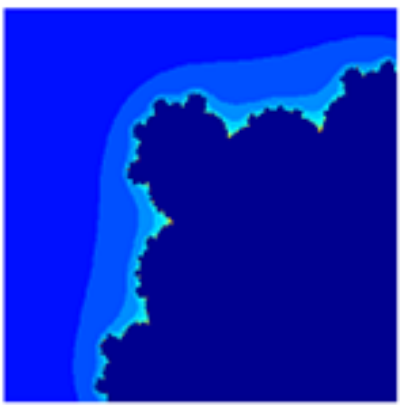

$b$
Fig. 3. The results of the construction of the classic Julia fractals $(a)$ and Mandelbrot fractals $(b)$ in the Matlab environment

In accordance with relaxation theory by Dissado Hill [10] due to the attractive forces in liquids (water) are formed area with a locally ordered structure - clusters, structure, composition and the energy value of the chemical bonds between molecules which depend on the type of liquid and solid medium, in which it is situated. In each of the liquid there are the basic, typical for it, clusters that define its structure.

In a two-level model, the relaxation of a group of atoms or molecules (cluster) associated with transitions from one minimum to the other two variants of the orientation corresponding to the minima in the potential curve (Fig. 4).

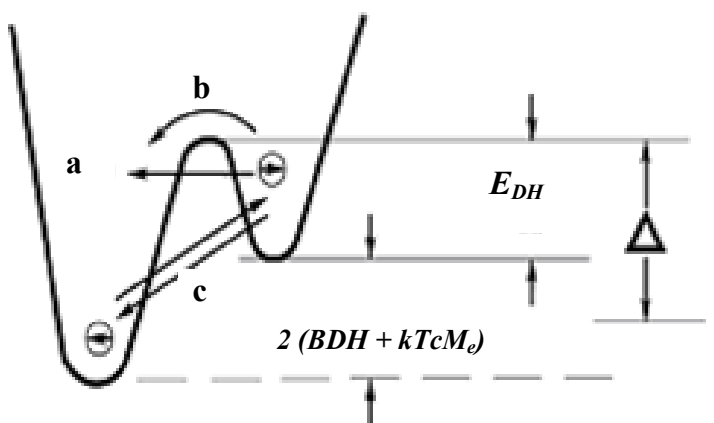

Fig. 4. Energy diagram of a two-layer system: $a$ - process related with rotational and vibrational intramolecular oscillations, $b$ - intra-cluster activation relaxation process, $c$-inter-cluster process of simultaneous exchange of molecules

The difference in energy values between these two minima, i.e. height of the barrier, which is overcome by the synchronous exchange of molecules between adjacent clusters is written explicitly as

$$
\Delta \varphi=2\left(B_{D H}+k T_{c} M_{e}\right),
$$

where $k$ is the Boltzmann constant, $T_{c}$ critical characteristic temperature (the phase transition temperature, for example, the glass transition temperature), $M_{e}$ is the unit vector of the longitudinal component of the dipole moment of the cluster

$$
M_{e}=\tanh \left(\frac{B_{D H}+k T_{c} M_{e}}{k T}\right) .
$$

The degree of structural ordering of the minimum size of the average cluster is characterized by the parameter $0 \leq n_{D H} \leq 1$. At $n=0$ the clusters are not formed, and the correlation between the processes of reorientation of molecules absents. When $n=1$ the clusters have a crystal structure in which the processes of molecules reorientation are fully correlated. Clusters, in their turn, are part of the inter-cluster formations, the degree of structural order in which is determined by the parameter $1-m_{D H}$, and $0 \leq m_{D H} \leq 1$. Boundary values $m_{D H}=0$ and $m_{D H}=1$ correspond to a perfect crystal lattice and the liquid with an ideal hydrodynamic flow.

For the cluster model by Dissado - Hill the dispersion relative electrical permittivity $\varepsilon^{*}(\omega)$ is described by the equation

$$
\frac{\varepsilon^{*}(\omega)-\varepsilon_{\infty D H}}{\varepsilon_{S}-\varepsilon_{\infty D H}}=\left(1+\frac{i \omega}{\omega_{p}}\right)^{n-1} \frac{2 F_{1}\left[1-n, 1-m ; 2-n ;\left(1+\frac{i \omega}{\omega_{p}}\right)^{-1}\right]}{{ }_{2} F_{1}(1-n, 1-m ; 2-n ; 1)},
$$

where $\varepsilon_{\propto D H}$ is the high-frequency limit of the area of dispersion, polarization due to the contribution of the fast polarization species (ion and electron bias) and a highfrequency relaxation process, ${ }_{2} F_{1}[\ldots]$ are the Gaussian hypergeometric functions.

The above equation corresponds to the Debye equation for $n=0, m=1, \omega_{p}=\tau_{D}^{-1}$. Maximum of dielectric losses $\varepsilon^{\prime \prime}$ takes place at $\omega=\omega_{p}$ only in the case $n=m$.

At each temperature there is a distribution of clusters in shape and size, which correspond to the mean-square square of the dipole moment of the cluster $\left\langle\begin{array}{c}- \\ \mu_{c}^{2}\end{array}\right\rangle$. 
The goal of the paper is investigation of features of manifestation of the relaxation losses in high-frequency range in polyethylene insulation at aging of samples of power and RF cables in high humidity conditions.

Test objects. As test objects samples of the coaxial cables are used.

1. A new power cable of voltage of $35 \mathrm{kV}$ in singlephase design with cross-section of aluminum conductors of $95 \mathrm{~mm}^{2}$ with the cross-linked (thermosetting) polyethylene insulation, semiconducting shields for conductor and insulation, copper screen. Design feature is the presence of semi-conductive hydrophilic water swelling tapes, providing radial cable protection from moisture.

2. A RF cable PK-50 with a two-layer thermoplastic polyethylene insulation without additional radial moisture protection. Cable for 5 years was in the room, and the cable ends were not sealed with heat-shrinkable protective caps.

3. A new RF cable EH4 (PK-75) with a thermoplastic foam polyethylene insulation without additional radial moisture protection.

4. A RF cable RG-6 (PK-75) with a thermoplastic foam polyethylene insulation and protection against moisture in the original (before operating) state as hydrophobic jelly after exploitation for 10 years.

Dynamics of changes in the relaxation losses during hydration. Test samples of the new power cable and cable PK-50 were subjected to aging in high humidity at room temperature for 1440 hours ( 2 months). In the initial state and after aging the dielectric loss tangent in the frequency range $50 \mathrm{kHz}-20 \mathrm{MHz}$ by Q-meter VM 560 using resonance method were measured (Fig. 5).

For samples of RF cables EH-4 and RG-6 with foam insulation measured frequency dependence on the dielectric loss tangent are shown in Fig. 6.

Analysis of the frequency dependences shows that there is a manifestation of the general laws of the relaxation losses in the cables. So, for the power cable with thermosetting and RF cable PK-50 with thermoplastic polyethylene insulation (Fig. 5) in the initial state and after the aging the nature of the frequency dependences of dielectric loss tangent is identical.

In the initial state we can see the relaxation maximum $\mathbf{I}$, whose width $\Delta f$ is indirectly related to the amount of moisture in the insulation: in a new power cable residual free moisture is considerably less than in the cable PC-50, which was a long time at natural conditions. After aging on the frequency dependence of the relaxation there are additional peaks II and III, related to the reorientation of polar water molecules in formed new clusters of different shapes and sizes.

In the new cable EH-4 (see Fig. 6,a) there are three characteristic relaxation peaks associated with the manifestation of the dipole polarization of water in clusters of different shapes and sizes. In the structure of the foamed thermoplastic polyethylene insulation there are gaseous inclusions, which are filled with water, as in the initial state and during operation (see Fig. 6,b).
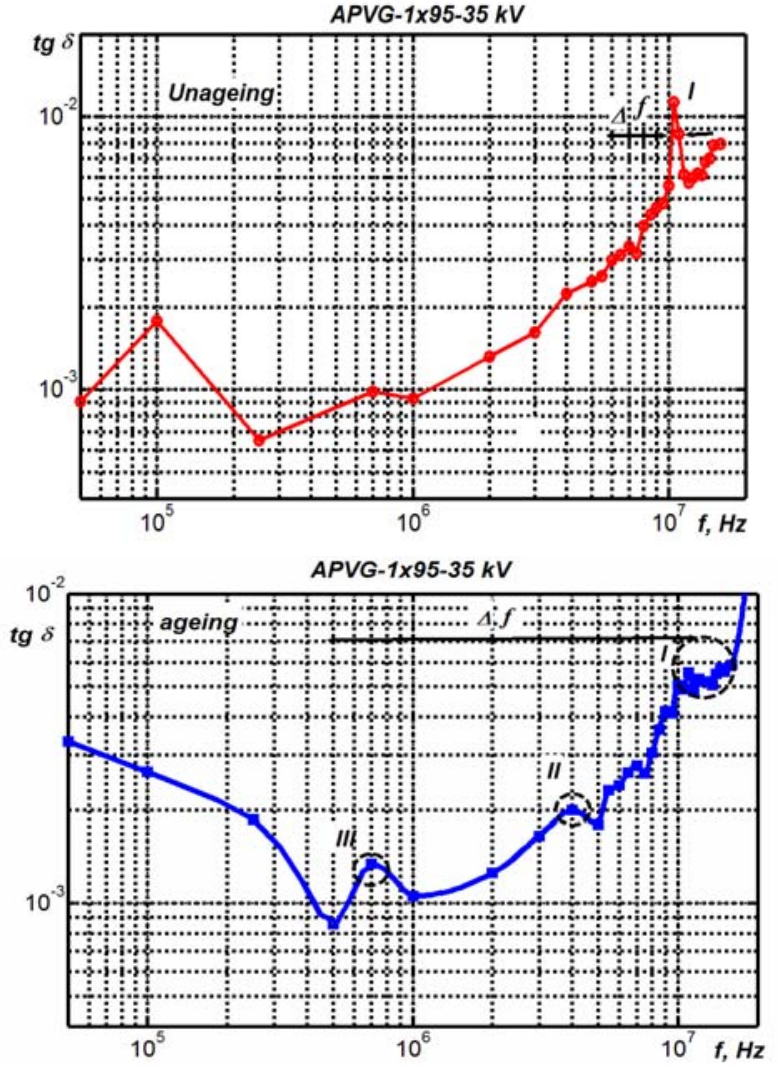

$a-$ a power cable with a thermosetting polyethylene insulation (top picture - the original state, bottom picture - after moistening)
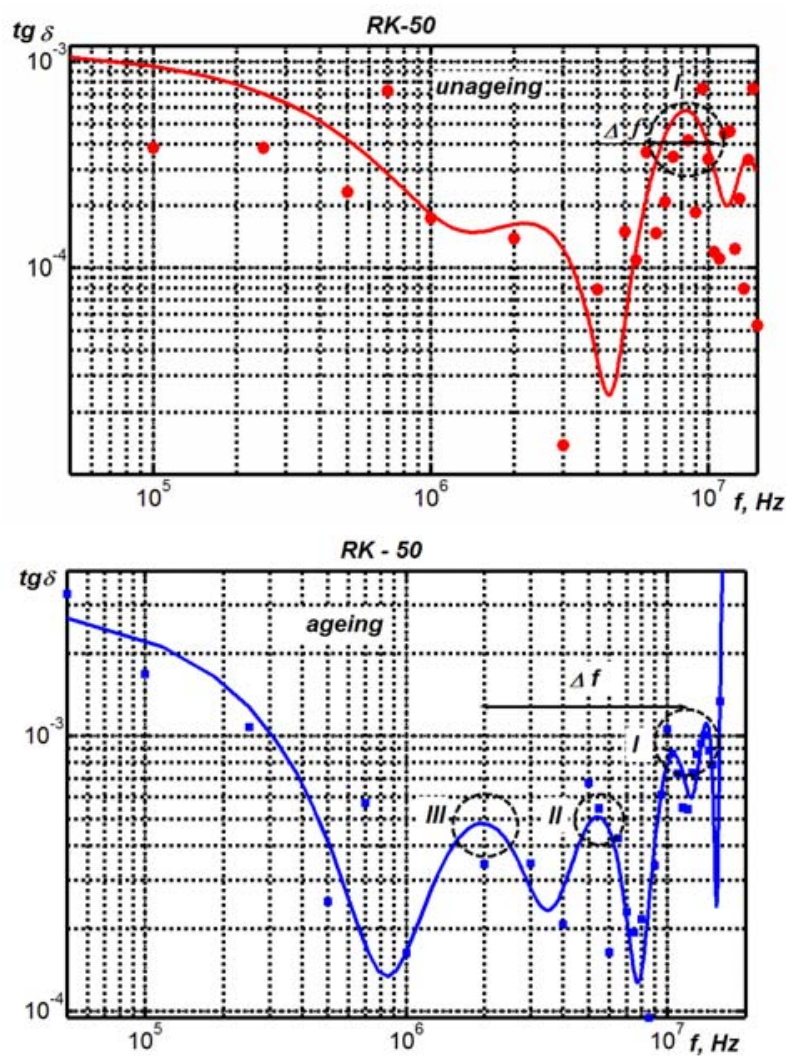

$b-$ a RF cable with a thermosetting polyethylene insulation (top picture - the original state, bottom picture - after moistening)

Fig. 5. Dynamics of changes in the tangent of the angle of dielectric losses in cables samples in the process of moistening 

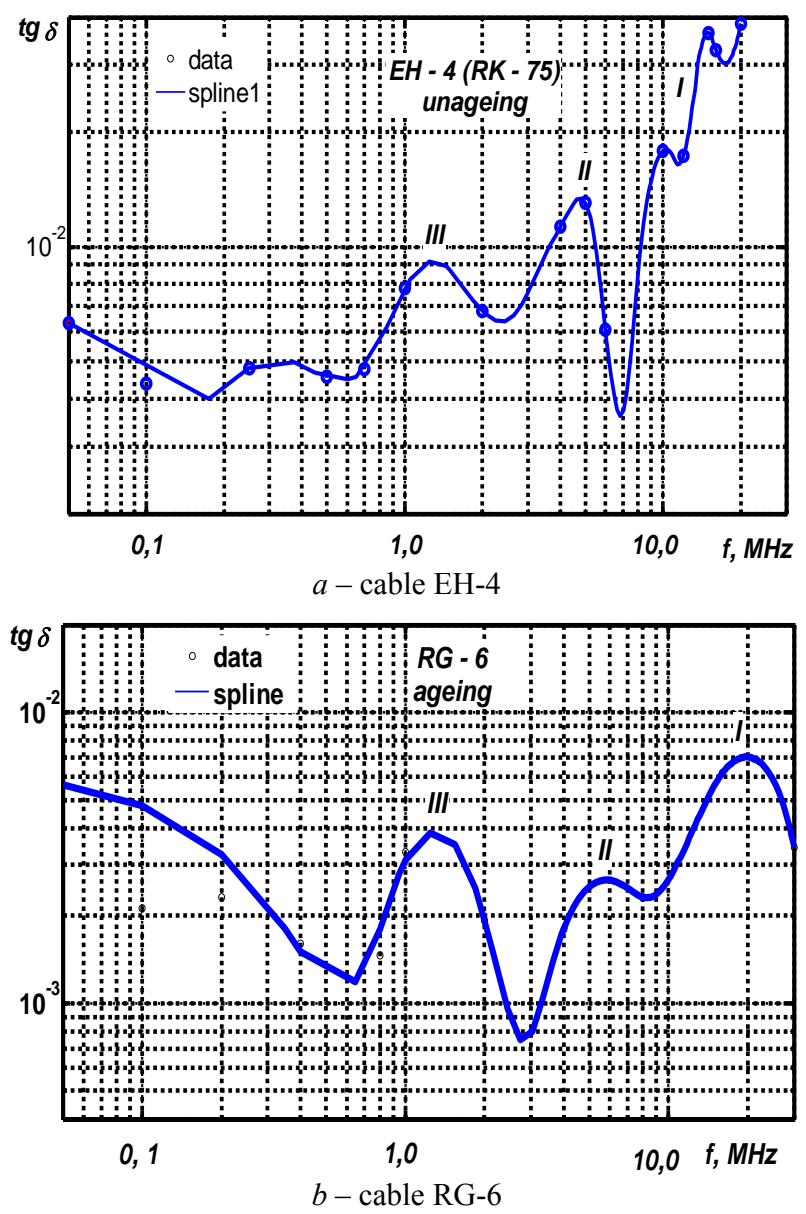

Fig. 6. The frequency dependence of the dielectric loss tangent of RF cables with foam thermoplastic polyethylene insulation

The correlation between the width of the spectrum of the dipole peaks and insulation resistance. Fig. 7 shows the results of the insulation resistance measurement of the power cable samples (curves 1 and 1') and radio frequency cable PK-50 (curves 2 and 2') depending on the applied DC voltage: curves 1 and 2 - the initial state, curves $1^{\prime}$ and 2 ' - after moistening.

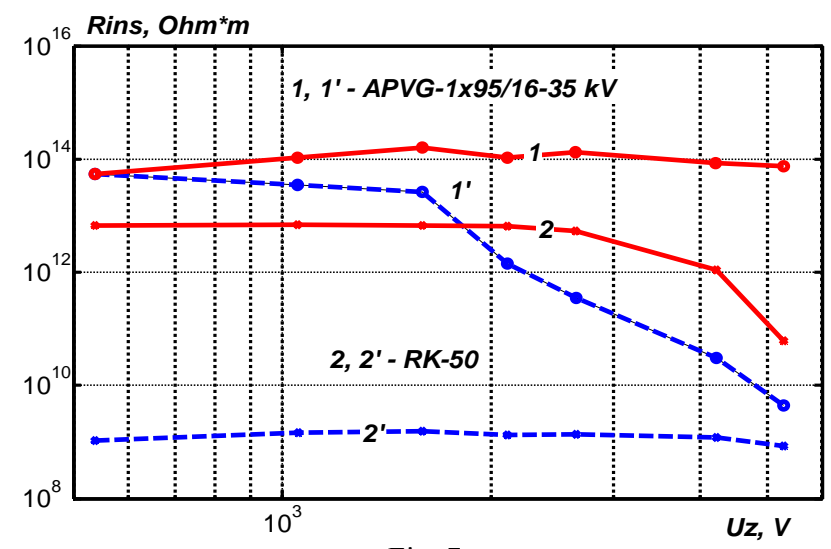

Fig. 7

In the initial state, the insulation resistance of the power cable is weakly dependent on the applied voltage (Fig. 7, curve 1). The spectral width $\Delta f$ of the relaxation maximum I (Fig. 5, $a$, the upper picture) is small. For RF cable PK-50 in the initial state the width spectrum $\Delta f$ of the relaxation maximum I (Fig. 5,b, the upper picture) is significant (about $6 \mathrm{MHz}$ ), which causes a decrease in the insulation resistance in 10 times when the voltage increases 10 times (from 500 to $5000 \mathrm{~V}$ ) (Fig. 7, curve 2).

After aging for the power cable (Fig. 7, curve 1') we observe the strongly expressed dependence of insulation resistance on the applied voltage: when the voltage is increased by 10 times the insulation resistance decreased to 10,000 times. The bandwidth of the spectrum $\Delta f$ of the relaxation maxima I - III (Fig. 5, the lower picture) increased almost 20 times.

For cable PK-50 spectral width $\Delta f$ of the relaxation maxima I - III (see Fig. 5,b, the lower picture) increased only 6 times, and as a result, the insulation resistance after moisture is practically independent on the voltage. For voltage of $5 \mathrm{kV}$ after aging the insulation resistance decreased to 100 times relative to the initial state. Obviously, in a thermoplastic polyethylene insulation water clusters with similar fractal dimensions are formed.

\section{Conclusions.}

So, the evidence of the existence in the polymeric insulation of the cables of free water in the form of areas with a locally ordered structure - clusters is experimentally found.

In the range of measurements of $50 \mathrm{kHz}-20 \mathrm{MHz}$ it is found that for solid plastic insulation at frequency dependences of dielectric loss tangent one maximum of relaxation takes place at $10 \mathrm{MHz}$ in the initial state and additional peaks appear in the frequency range $500 \mathrm{kHz}-$ $5 \mathrm{MHz}$ after moistening. For thermosetting (crosslinked) polyethylene insulation large width $\Delta f$ of the frequency spectrum in which relaxation losses take place is characterized. Obviously, the width of each of the relaxation peaks is related to the characteristic fractal cluster size.

It is important that in the hydrated solid and foamed polyethylene insulation individual, typical only for water clusters detected by high-frequency relaxation dipole maxima of the dielectric loss tangent take place.

There is a positive correlation between the bandwidth $\Delta f$ of the relaxation maxima and insulation resistance decrease rate on the applied high DC voltage.

\section{REFERENCES}

1. De Bellet J., Matey G., Rose L., Rose V., Filippini J., Poggi Y., Raharimalala V. Some aspects of the relationship between water treeing, morphology, and microstructure of polymers. IEEE Trans. Elect. Insul., 1987, vol.EI-22, no.2, pp. 211-217. doi: $10.1109 /$ tei.1987.298884.

2. Ciuprina F., Teissèdre G., Filippini J.C. Polyethylene crosslinking and water treeing. Polymer, 2001, vol.42, no.18, pp. 7841-7846. doi: 10.1016/s0032-3861(01)00264-6.

3. Dissado L.A. Understanding electrical trees in solids: from experiment to theory. IEEE Trans. Dielect. Electr. Insul., 2002, vol.9, no.4, pp. 483-497. doi: 10.1109/tdei.2002.1024425.

4. Kato T., Yamaguchi T., Komori F., Kawahara T., Hidaka T., Suzuoki Y. Influence of structural change by $\mathrm{AC}$ voltage prestressing on electrical-tree inception voltage of LDPE with water-tree degradation. 2012 Annual Report Conference on Electrical Insulation and Dielectric Phenomena, Montreal, Canada: IEEE, 2012, pp. 847-850. doi: 10.1109/ceidp.2012.6378913.

5. Shcherba A.A., Podoltsev A.D., Kucheriavaia I.N., Zolotarev V.M. Electric transport of polar water molecules in an 
inhomogeneous electric field of polymer insulation high-voltage cables. Tekhnichna elektrodynamika - Technical Electrodynamics, 2010, no.5, pp. 3-9. (Rus).

6. Priya S., Mubashira Anjum A. Analysis of water trees and characterization techniques in XLPE cables. Indian Journal of Science and Technology, 2014, vol.7(S7), pp. 127-135.

7. Shuvalov M.Y., Mavrin M.A. Theoretical and experimental research water treeing type of «bow». Kabeli i provoda-Cables and wires, 2002, no.1, pp. 44-50. (Rus)

8. Mandelbrot B.B. Fractals: form, chance and dimension. San Francisco: Freeman, 1977.

9. Dissado L.A., Hill, R.M. The fractal nature of the cluster model dielectric response functions. Journal of Applied Physics, 1989, vol.66, no.6, pp. 2511-2524. doi: 10.1063/1.344264.
10. Dissado L.A., Hill R.M. A cluster approach to the structure of imperfect materials and their relaxation spectroscopy. Proceedings of the Royal Society A: Mathematical, Physical and Engineering Sciences, 1983, vol.390, no.1798, pp. 131-180. doi: 10.1098/rspa.1983.0125.

Received 28.12.2015

G.V. Bezprozvannych ${ }^{1}$, Doctor of Technical Science, Professor, A.G. Kyessayev ${ }^{1}$, Postgraduate Student,

${ }^{1}$ National Technical University «Kharkiv Polytechnic Institute», 21, Frunze Str., Kharkiv, 61002, Ukraine. phone +380 577076010 ,

e-mail: bezprozvannych@kpi.kharkov.ua

How to cite this article:

Bezprozvannych G.V., Kyessayev A.G. Relaxations losses in polyethylene insulation of coaxial cable structure during aging in high humidity conditions. Electrical engineering \& electromechanics, 2016, no.2, pp. 38-42. doi: 10.20998/2074-272X.2016.2.07. 